\title{
INFORME DE AVITE
}

\section{REPORT OF AVITE}

José Riquelme López: Asociación de Víctimas de Talidomida y otras Inhabilidades de España (AVITE)

jose.riquelme@ozu.es

\section{CURRÍCULUM VITAE}

Presidente de la Asociación de Víctimas de Talidomida y otras Inhabilidades de España (AVITE). Destaca por su labor de lucha por el reconocimiento de los afectados por dicha droga a nivel nacional e internacional.

\section{RESUMEN}

En este artículo se recogen diferentes documentos de la Asociación de Víctimas de Talidomida y otras Inhabilidades de España, informes sobre la situación actual de las víctimas en España, los cambios que se van a producir gracias al interés del presidente del Gobierno, José Luis Rodríguez Zapatero y el Príncipe Don Felipe de Borbón, y las denuncias que va a hacer la Asociación en la próxima reunión.

\section{PALABRAS CLAVE}

Talidomida - España - Denuncias - Cambios 


\begin{abstract}
This article shows different documents Thalidomide Victims Association and other Disabilities in Spain, reports on the current status of the victims in Spain, the changes that will occur thanks to the interest of Prime Minister Jose Luis Rodriguez Zapatero and Prince Felipe de Borbon, and allegations that the Association will make the next meeting.
\end{abstract}

\title{
KEY WORDS
}

Thalidomide - Spain - Complaints - Changes

\section{ÍNDICE}

1. Informe para la Fundación Ishizue, 9, 10 y 11 de octubre Tamachi-Tokyo (Japón) sobre la situación actual de las víctimas españolas y la situación actual de la droga en España.

1.1. Situación actual de las victimas de Talidomida en España: antecedentes

1.2. Cambio radical

1.3. Situación actual de la Talidomida en España

\subsection{Conclusiones}

2. Entrevista del presidente de la asociación de víctimas de talidomida inglesa thalidomide.uk, con el presidente de la asociación española

3. Comunicado de prensa de AVITE I: sobre las denuncias que la Asociación de Víctimas de Talidomida de España (AVITE), va a hacer al mundo en Tokio, el próximo día 11 de octubre de 2004 
4. Comunicado a la prensa de AVITE II: sobre la reunión del día 29 de julio de 2004 mantenida por representantes de AVITE con Fernando la Mata Cotanda, Secretario General de Sanidad, en el Ministerio de Sanidad, en Madrid

\section{TEXTO:}

\section{Informe para la Fundación Ishizue, 9, 10 y 11 de octubre Tamachi- Tokyo (Japón) sobre la situación actual de las víctimas españolas y la situación actual de la droga en España.}

1.1. Situación actual de las victimas de Talidomida en España: antecedentes

Durante más de 40 años, las víctimas españolas de Talidomida, hemos estado desasistidas, y sometidas a una represión total y nos han tenido la boca tapada todos los gobiernos españoles.

Los diferentes gobiernos españoles, hasta hace pocos meses, siempre habían negado que se vendiese Talidomida en España y, por tanto, también negaban la existencia de víctimas en España. Por ello nunca confeccionaron ningún censo ni registro oficial.

Esta Asociación, con la ayuda de la prensa, la TV y de otros medios de comunicación, se ha encargado de demostrar a la sociedad española todo lo contrario.

Sólo conocemos 1 caso español recompensado económicamente por el gobierno Alemán. Es el vicepresidente de esta Asociación.

Esta Asociación Española se creó y nació en Septiembre del año 2003, y barajamos la cifra de 1.000 posibles víctimas que la droga pudo producir en España en la década 
de los años 50 y 60. Esta cifra la damos como hipotética, porque no existe ningún censo ni registro oficial, y la damos como probable, por los siguientes motivos:

a) La media de medicamentos que se vendieron en cada país, fue 3 ó 4 medicamentos por país.

b) En Gran Bretaña, por ejemplo, fueron 5 medicamentos los que se vendieron, y produjo 450 casos.

c) En todos los países se retiró en 1961 o 1962. En España en 1963.

d) Por ello y debido a que en España fue ampliamente recetada por médicos, hospitales y farmacéuticos. Debido también a que fueron 7 medicamentos los que se comercializaron en España y que se retiró en 1963, estimamos que puede ser una cifra cercana a 1.000 casos, o quizás más.

e) Al ser una Asociación relativamente joven, porque tiene pocos meses de vida, de momento sólo contamos con 40 miembros afiliados y asociados.

\subsection{Cambio radical}

El nuevo Presidente del Gobierno, José Luis Rodríguez Zapatero, del Partido Socialista, y el Príncipe de España, D. Felipe de Borbón, han mostrado su interés y solidaridad en nuestras peticiones y reivindicaciones justas, y se han solidarizado con nosotros.

Después de pedir insistentemente justicia, esta Asociación está siendo escuchada por el gobierno español actual. 
Por ello, el gobierno actual, los días 10 de junio y 29 de julio, se ha reunido con miembros de AVITE en Madrid, y se ha comprometido con esta Asociación Española a elaborar un calendario de reuniones de trabajo, durante 6 meses con el gobierno, para estudiar conjuntamente todas nuestras reivindicaciones, y que son éstas:

1.- Creación de una Comisión Médica para la evaluación y catalogación de las posibles víctimas españolas.

2.- Creación de una Comisión Médica que estudie periódicamente las degeneraciones físicas que produce en los cuerpos de las víctimas.

3.- Creación de un Equipo médico psicológico para tratamiento de víctimas y sus familiares directos.

4.- Campaña del Estado en TV para ayudar a que salgan de sus casas todas las victimas de Talidomida en España, y se olviden de la vergüenza social.

5.- Elaboración de una Ley en el Parlamento para abrir nuevos plazos para posibles indemnizaciones, con fondos económicos aportados por las empresas farmacéuticas.

6.- Beneficios Fiscales para las víctimas.

7.- Creación de una Fundación que encauce todas las necesidades de las víctimas, gestionada por las propias víctimas españolas.

Estamos en un momento político de cambio en España y eso beneficia a las víctimas de Talidomida en España. 
El anterior Presidente del Gobierno, José Maria Aznar y su Ministra de Sanidad, Ana Pastor, ambos del Partido Popular, no contestaban a nuestras cartas, y siempre se negaron a recibirnos en Madrid.

Colectivos profesionales de periodistas, abogados y médicos, nos están apoyando desinteresadamente.

Por ello también, esta Asociación Española agradece a la Fundación Ishizue esta oportunidad tan importante que ha ofrecido a las Asociaciones de todo el mundo, para poder expresarnos con libertad, y poder comunicar al mundo la problemática española y nuestra lucha. Queremos seguir en esta buena línea de unión entre todas las asociaciones del mundo, las cuales deben estar estrechamente unidas, por el bien de todos.

\subsection{Situación actual de la Talidomida en España}

a) Actualmente se puede comprar Talidomida en España en Internet con total facilidad e impunidad, ya que cientos de farmacias virtuales en sus páginas webs la ofrecen a bajo precio y sin control, incluso indicando sus propias direcciones postales.

b) Se está facilitando a los enfermos de mieloma en todos los hospitales españoles y europeos en uso compasivo. (Algunos hospitales la compran en el mercado negro, porque es más barata).

c) Hasta el 15 de julio de 2003, la ha estado regalando el laboratorio alemán Chemie Grünenthal a todos los hospitales europeos y españoles. 
d) A partir del 16 de julio de 2003, la vende en todos los hospitales europeos y españoles para uso compasivo el laboratorio Pharmion, al precio de 319 Euros una caja de 28 cápsulas, cuando el costo de fabricación de la materia prima de esa caja son 10 céntimos de Euro. (En el mercado negro, su precio es de 228 Euros).

e) Pharmion ha retirado provisionalmente la licencia ante la Unión Europea y la EMEA, pero sigue facilitándola a los hospitales europeos en uso compasivo para mieloma. Y sigue adelante con la solicitud de la licencia en Europa para la Lepra.

f) El laboratorio Pharmion obtiene dinero con la Talidomida en la actualidad, por 4 vías diferentes: 1) Mercado Negro. 2) Uso Compasivo. 3) Como medicamento huérfano. 4) En los países en los que ha obtenido la licencia de venta.

g) Pronto anunciarán en la Unión Europea la panacea de que la Talidomida también cura el acné, y las chicas jóvenes la compraran a bajo precio en Internet, sin control, y con el grave riesgo que ello supone si quedan embarazadas.

h) Los precios que se cobran por la Talidomida, tanto en las farmacias de los países donde está legalizada, como en las farmacias de los hospitales, e incluso en el mercado negro, son escandalosos.

i) Las policías de todo el mundo no actúan y no persiguen el mercado negro, a pesar de que esta Asociación ha facilitado todas las pruebas disponibles a todos los gobiernos anteriores españoles.

j) Esta asociación también entregó a la EMEA las pruebas que tenemos del mercado negro, y tampoco actúa para cortarlo de raíz y perseguir judicialmente a sus responsables. 
k) Hemos denunciado en diversos foros que el responsable máximo de la venta en Internet es el fabricante Penn Pharmaceuticals, que está ubicado en el País de Gales y que vende Talidomida por igual, tanto al mercado negro, como al mercado legal. Pero nadie actúa.

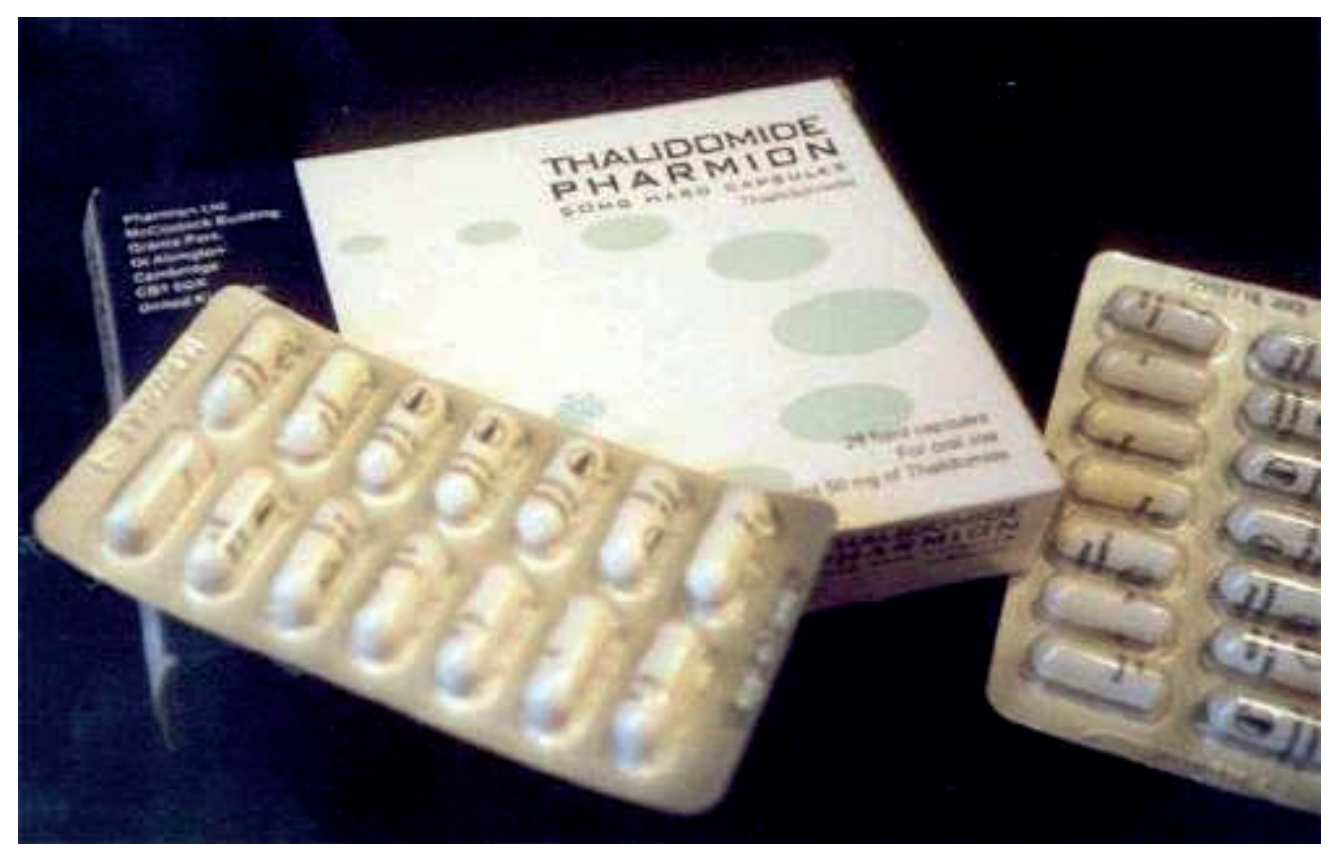

Talidomida comprada en el mercado negro, por las propias víctimas de Talidomida, para demostrar que el Control de Riesgos impuesto por la Unión Europea, no funciona.

\subsection{Conclusiones}

Acompañamos una presentación en PowerPoint con fotografías de algunas de las víctimas españolas de Talidomida.

Consideramos y sugerimos que estos encuentros deberían celebrarse anualmente, en diferentes países, puesto que consideramos que es muy positivo poder intercambiar información e inquietudes, validas para todas las victimas de Talidomida del mundo. 
Webs Asociación Victimas Talidomida España: www.linneo.net/avite www.asociaciontalidomida.galeon.com

Email: asociaciontalidomidaespana@alcantarilla.es

Email: jriquelope@hotmail.com

Foro Talidomida en España: http:/ / www.foros.hispavista.com/talidomida

Tel.: 639169393

C/ Comadrona Carmen Cascáles Carmita, 1-2 ${ }^{\circ}-\mathrm{H}$

C.P.: 30820 ALCANTARILLA (Murcia) ESPAÑA/SPAIN

$\mathrm{N}^{\mathrm{o}}$ Insc. Rtro. Ministerio Interior: 171.733 Secc. $1^{\mathrm{a}}$

$\mathrm{N}^{\mathrm{o}}$ Insc. Rtro. Com. Auton. Murcia: 7.536 Secc. $1^{\mathrm{a}}$

CIF ASOCIACIÓN: G73303026

Federación Mundial Asociaciones Víctimas Talidomida:

www.thalidomideworldwide.com

Periódico/magazín sobre Talidomida: www.thalidomideuk.com

Chat Talidomida: http:/ / groups.msn.com/ThalidomideInternational

http://groups.yahoo.com/group/thalidomideint/

\section{Entrevista del presidente de la asociación de víctimas de talidomida inglesa thalidomide.uk, con el presidente de la asociación española}

Freddie Astbury, Presidente de Thalidomide UK, Asociación inglesa de victimas de talidomida, que engloba a 450 víctimas británicas de la feroz droga que arrasó el planeta y el Reino Unido en los años 50 y 60, visitará España y concretamente Benidorm y Murcia, del 18 al 25 de septiembre de 2004.

El motivo central de su visita es entrevistarse con el presidente de esta Asociación española AVITE, José Riquelme, para comprobar, in situ y de primera mano, cómo marchan las negociaciones entre AVITE y las autoridades sanitarias del Gobierno 
Español, después de que este último, haya escuchado las reivindicaciones de las víctimas españolas de talidomida.

Freddie Astbury, residente en Liverpool, que nació sin brazos y sin piernas, con tan sólo el tronco del cuerpo y cabeza, a causa de la talidomida, permanecerá durante una semana en España, manteniendo diversos contactos y reuniones de trabajo.

\section{Comunicado de prensa de AVITE I sobre las denuncias que la Asociación de Víctimas de Talidomida de España (AVITE), va a hacer al mundo en Tokio, el próximo día 11 de octubre de 2004}

Coincidiendo con el encuentro de todas las Asociaciones del Mundo de Victimas de Talidomida, organizado por la Fundación de Victimas Japonesa Ishizue, para conmemorar el 30 aniversario de la creación de dicha fundación, la Asociación de Víctimas de Talidomida de España AVITE, el próximo día 11 de octubre DE 2004, en Tokio, va a denunciar y a exponer al mundo:

1. La situación denigrante que arrastran las víctimas españolas de Talidomida, que durante más de 40 años hemos sido ignorados y humillados por todos los gobiernos anteriores.

2. También se expondrá y podrán visualizar los asistentes y los representantes de los diversos medios de comunicación que acudirán a la reunión de Tokio, en una Presentación en PowerPoint, todas las pruebas de que dispone esta Asociación española, para demostrar y desmontar la idea de que en España no se había vendido Talidomida y de que no había victimas: AVITE tiene las pruebas de todo: frasquitos, Vademécum, victimas por doquier, etc. Informaremos también que el nuevo Gobierno Español, recientemente elegido, se está reuniendo con nosotros y nos ha 
prometido que en próximas reuniones, atenderá todas nuestras peticiones y reivindicaciones.

3. También denunciaremos la existencia de diversos mercados negros de Talidomida en Internet en los Club de Compradores o Clubs de Buyer, o farmacias virtuales, sin que nadie actúe ni controle su venta, y demostraremos que los controles de riesgos impuestos por la EMEA (Agencia de Evaluación de los Medicamentos) y la U.E., no funcionan, y para demostrarlo, nosotros mismos la hemos comprado en Internet.

4. Denunciaremos quién está detrás del mercado negro de Talidomida.

5. Pronto anunciarán, como ya hizo hace unos años EE.UU, la panacea de que cura el Acné. El riesgo y el peligro es muy grande, sobre todo para la gente joven que la adquiera en Internet, a bajo precio.

6. Denunciaremos los precios escandalosos de la Talidomida actuales, con los que mucha gente se quiere enriquecer a costa de ella y de las victimas de antaño.

4. Comunicado a la prensa de AVITE II sobre la reunión del día 29 de julio de 2004 mantenida por representantes de AVITE con Fernando la Mata Cotanda, Secretario General de Sanidad, en el Ministerio de Sanidad, en Madrid

El 29 de julio de 2004, representantes de AVITE se reunieron con el Gobierno español, en una segunda reunión de trabajo, en la persona de Fernando Lamata Cotanda (Secretario General de Sanidad), en el Ministerio de Sanidad en Madrid. 
La valoración de esta segunda reunión es positiva al $100 \%$.

El representante del Gobierno español, escuchó todas y cada una de las peticiones y reivindicaciones médicas y sociales de los representantes de AVITE, y las calificó de justas y accedió a estudiar todas y cada una de ellas con su equipo de colaboradores más directos.

Esta reunión se celebró por encargo expreso de la Sra. Ministra de Sanidad, la cual quiere que se le dé prioridad a las peticiones de las víctimas españolas de talidomida.

Fernando Lamata, se ha marcado el plazo de un semestre para estudiar todas y cada una de las peticiones de AVITE en reuniones conjuntas de trabajo, y que son las siguientes:

- Comisión Médica para la evaluación de las posibles víctimas, que dictaminará con las pruebas oportunas, quién fue y quien no, afectado por talidomida en España.

- Comisión Médica que estudiará y hará revisiones periódicas anuales a las víctimas españolas, para estudiar las posibles degeneraciones físicas, que la talidomida puede producir día a día en los cuerpos de los afectados de antaño.

- Equipo psicológico para el tratamiento de las víctimas y sus familiares directos.

- Campaña institucional para intentar que salgan a la luz, y de sus casas, las víctimas de la talidomida en España, y que dejen de una vez su vergüenza social; en colaboración y con ayuda de las Comunidades Autónomas, a las que se les pedirán datos de sus ficheros y bases de datos, para también conseguir información de posibles afectados de antaño, y con ello crear un censo definitivo. 
- Elaboración de una Ley en el Parlamento, para abrir nuevos plazos para posibles indemnizaciones, con fondos aportados por las empresas farmacéuticas.

Después de más de 40 años, los gobiernos anteriores no quisieran nunca recibirnos, ni contestar a nuestras cartas y reivindicaciones, e intentaron sepultarnos en vida.

El Gobierno actual, en un gesto que le honra, nos ha escuchado, y nos ha quitado la tierra que otros echaron en nuestra sepultura en vida, y van a tratar de ayudarnos. 